\title{
Use of fish community data to evaluate restoration success of a riparian stream
}

\author{
Michael H. Paller ${ }^{\mathrm{a}, *}$, Marcel J.M. Reichert ${ }^{\mathrm{b}}$, John M. Dean ${ }^{\mathrm{b}}$, \\ John C. Seigle ${ }^{\mathrm{b}}$ \\ ${ }^{a}$ Environmental Analysis Section, Building 773-42A, Westinghouse Savannah River Company, Aiken, SC 29808, USA \\ ${ }^{\mathrm{b}}$ Belle W. Baruch Institute for Marine Biology and Coastal Research, University of South Carolina, EWS 613, Columbia, \\ SC 29208, USA
}

Received 19 March 1999; received in revised form 1 June 1999; accepted 16 September 1999

\begin{abstract}
From 1985 to 1988, stream and riparian habitats in Pen branch and Four Mile branch began recovering from deforestation caused by the previous release of hot water from nuclear reactors. The Pen branch corridor was replanted with wetland trees in 1995 to expedite recovery and restore the Pen branch ecosystem. Pen branch, Four Mile branch, and two relatively undisturbed streams were electrofished in 1995/1996 to determine how fish assemblages differed between the previously disturbed and undisturbed streams and whether such difference could be used to measure restoration success in Pen branch. Fish assemblages were analyzed using nonparametric multivariate statistical methods and the index of biotic integrity (IBI), a bioassessment method based on measurement of ecologically sensitive characteristics of fish assemblages. Many aspects of fish assemblage structure (e.g. species richness, disease incidence, taxonomic composition at the family level) did not differ between disturbed and undisturbed streams; however, the disturbed streams were characterized by higher densities of a number of species. These differences were successfully detected with the multivariate statistical methods; whereas, the IBI did not differ between most recovering and undisturbed sampling sites. Because fish assemblages are strongly influenced by instream habitat, and because instream habitat is strongly influenced by the riparian zone, fish assemblages can be used to measure restoration success. Nonparametric ordination methods may provide the most sensitive measure of progress towards restoration goals, although the IBI can be used during early stages of recovery to indicate when certain ecologically important aspects of structure and function in recovering streams have reached levels typical of undisturbed streams. (C) 2000 Elsevier Science B.V. All rights reserved.
\end{abstract}

Keywords: Restoration; Streams; Fish; Indicators; Reforestation

\section{Introduction}

* Corresponding author. Tel.: + 1-803-7255250; fax: + 1803-7257673.

From 1954 to 1988 , high volumes of heated water were discharged from a nuclear reactor into

E-mail address: michael.paller@srs.gov (M.H. Paller). Pen branch, a third order stream located on the 
upper coastal plain of South Carolina. Extreme temperatures and scouring flows resulted in the destruction of aquatic and riparian vegetation and extensive erosion within the stream bed and riparian zone of Pen branch. Perhaps the most conspicuous change resulting from these discharges was loss of the forest canopy that previously shaded Pen branch. Following the cessation of reactor operations, natural processes of secondary succession began in Pen branch and contiguous riparian areas. In 1993-1995, the Pen branch corridor and delta were replanted with trees characteristic of local wetland and riparian climax forests with the objective of expediting the recovery process. Because the focus of the replanting was restoration of the Pen branch ecosystem, rather than just reforestation, there was interest in the collateral effects of the replanting on organisms other than trees. The fish assemblages in Pen branch were of interest because of their ecological importance and because of their possible future use as indicators of restoration success. Fish assemblages are widely used as indicators of biotic integrity in streams (Plafkin et al., 1989).

Biotic integrity is "the ability (of a stream) to support and maintain a balanced, integrated, adaptive community of organisms having a species composition, diversity, and functional organization comparable to that of natural habitats of the region' (Karr and Dudley, 1981; Angermeier and Karr, 1994). The index of biotic integrity (IBI) is a method of using fish assemblage data to assess biotic integrity. It is composed of a number of community, population, and organism level variables that are ecologically important and sensitive to environmental disturbances of various types (Karr et al., 1986). These variables are measured at assessment sites, compared with similar variables in a range of similar but relatively undisturbed benchmark streams, and the results summarized in a single number that reflects the extent to which the assessment site resembles the benchmarks. The IBI was originally developed for the mid-western United States but has been adapted for other regions (Plafkin et al., 1989), including the upper South Carolina coastal plain, where it has accurately discriminated between relatively undisturbed sites and sites affected by physical habitat alter- ations and chemical pollution (Paller et al., 1996).

Previous studies on the SRS demonstrated that the IBI is sensitive to the types of ecological changes associated with the discharge of heated water and the early stages of recovery ( 2 years following the cessation of discharge) once such discharge has ceased (Paller et al., 1996). However, sensitivity of the IBI to intermediate stages of recovery (herein defined as 10-15 years after the cessation of discharge) has not been investigated. Preliminary evidence suggests that these stages may not be characterized by patterns of fish assemblage structure (e.g. low numbers of species) typically associated with low biotic integrity. If this is the case, analysis of such patterns may be best accomplished by multivariate statistical techniques or other methods that can identify and summarize differences between disturbed and relatively undisturbed communities regardless of the nature of these differences.

The present study included four streams on the SRS that experienced different levels of impact from previous heated discharges and different periods of recovery since the cessation of discharge. Two streams that experienced no impact possessed mature forest canopies presumably representative of the end product of restoration success in Pen branch. The other two streams were in intermediate stages of succession as they progressed from a deforested state towards regrowth of a forest canopy. The basic objectives of this study were to determine if fish assemblages differed between streams with riparian zones in different stages of succession and if such differences could serve as a basis for evaluating restoration success. Methods used to summarize and evaluate the fish assemblage data included the IBI and several nonparametric multivariate statistical methods.

\section{Material and methods}

\subsection{Field methods for fish assemblage sampling}

We sampled a total of 13 sites in the lower reaches of Meyers branch, Upper Three Runs, Four Mile branch, and Pen branch during September, 1995 to January, 1996 (Table 1). Four 


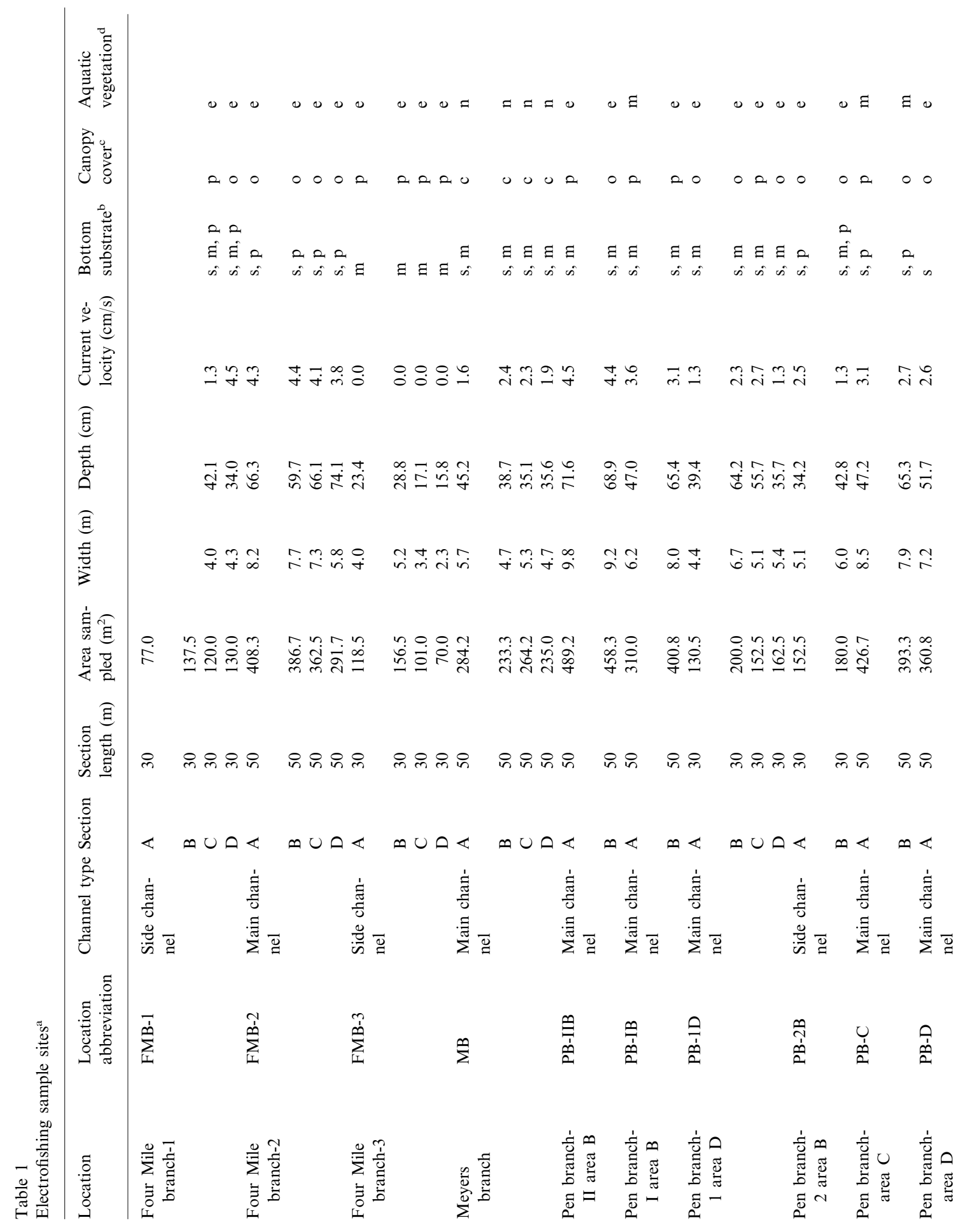




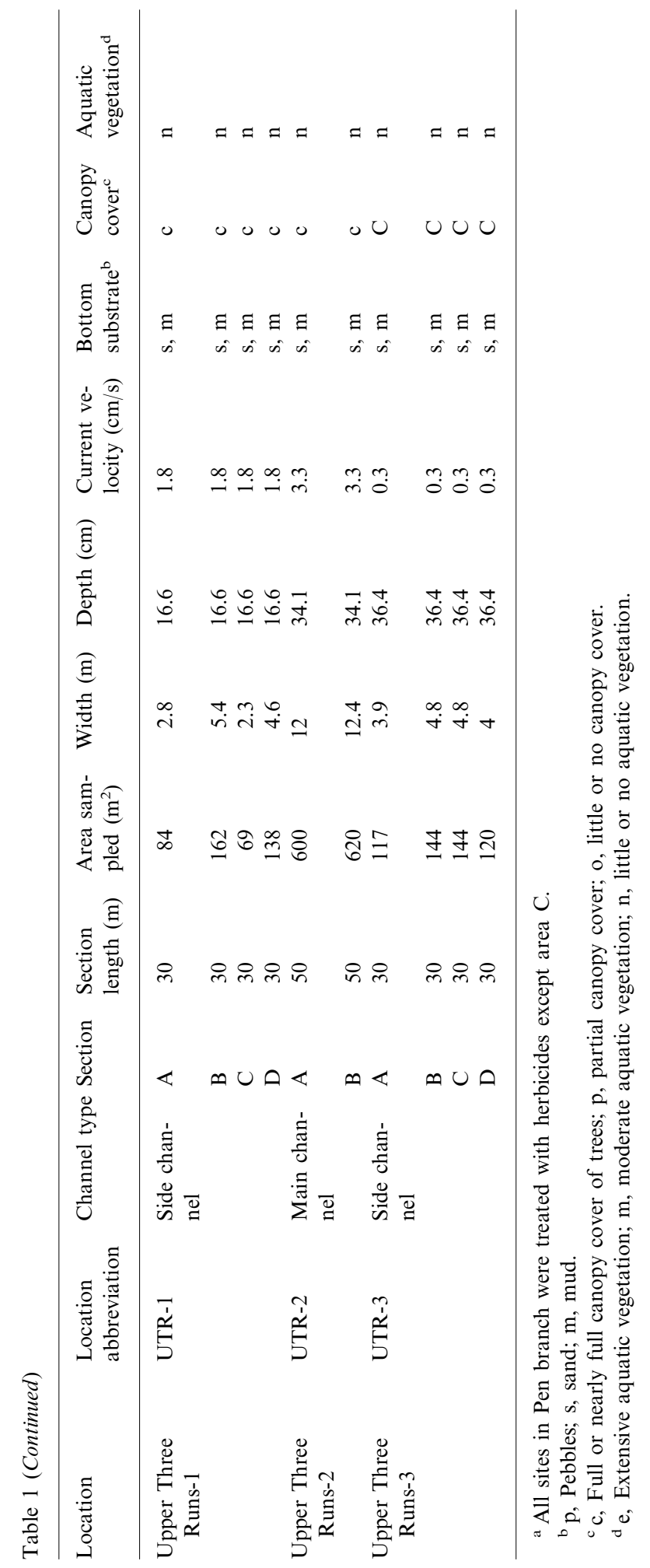




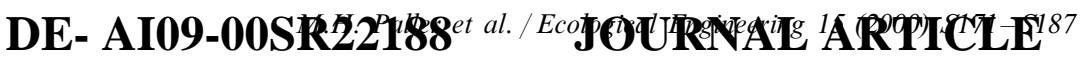

Mile branch and Pen branch formerly received heated water from $\mathrm{C}$ reactor and $\mathrm{K}$ reactor, respectively. C Reactor ceased operations in 1985, and $\mathrm{K}$ reactor ceased operations in 1988. Meyers branch and Upper Three Runs were relatively undisturbed streams selected because they were generally comparable to the formerly thermal streams in important factors that can influence fish assemblage structure such as width and depth. We selected sites within each stream to span the range of habitats present including main and side channels. Side channels were comparatively small channels lateral to large channels in braided stream reaches. The streams sampled in this study are described more fully in Fletcher et al. (2000).

We sampled one to four stream sections (A-D) between 30 and $50 \mathrm{~m}$ in length at each of the 13 sampling sites (Table 1). We used brightly colored marking tape to indicate the beginning and end of each section. The sampling gear consisted of a battery operated Smith Root backpack electroshocker (model 12-A POW). We sampled each section with three to five runs through the sampling area following Paller (1995)and Paller et al. (1996). A sampling crew consisted of a minimum of three people with one operating the shocker and all three collecting fish with 5-mm mesh dip nets. We sampled by carefully sweeping the complete stream width starting at the downstream marker and working to the upstream marker. We did not use block nets and took care to thoroughly sample around structures like submerged tree roots, logs, and plants. All fish were transferred to plastic trays filled with creek water. We recorded the total duration of each run (total time) and the time electricity was applied during that run (shocker time).

Upon completion of each run, we processed each fish by identifying it to species and checking it externally for lesions, malformations and parasites. We processed fish separately for each run and retained all fish until all runs were completed. Between consecutive runs, we left the creek for a short period to allow the water to clear. After the last run, we returned all unpreserved fish to the stream. Sampling at each site was completed within a few hours to 1 day. Specimens that could not be definitively identified in the field were preserved in $75 \%$ alcohol for identification in the laboratory. A sample of each species was kept and preserved in $75 \%$ alcohol for reference.

In addition to data collected during this study, we report (for comparative purposes) data collected from two main channel sample sites in the lower reaches of Pen branch during 1990. These sites were located approximately $1.0-1.5 \mathrm{~km}$ upstream from the sites sampled in 1995 and 1996 and were electrofished using similar methods. At the time of sampling, the habitat at these sites was generally comparable to the habitat at the other sample sites.

\subsection{Field methods for habitat characterization}

We measured a number of habitat variables in each section sampled during 1995 and 1996,

1. stream width (nearest $0.1 \mathrm{~m}$ ) perpendicular to the direction of stream flow at the beginning, end, and in the middle of each sampling section;

2. depth $(\mathrm{cm})$ at 25,50 , and $75 \%$ of the stream width at the beginning, end, and in the middle of each sampling section using a calibrated pole;

3. current velocity $(\mathrm{cm} / \mathrm{s})$ at 25,50 , and $75 \%$ of the stream width and at $60 \%$ of the depth using a global water current meter (if the depth was over $72 \mathrm{~cm}$, depth was measured at 20 and $80 \%$ of the depth. Measurements were done at the beginning, end, and in the middle of each sampling section);

4. predominant sediment type(s) within each section (visually estimated as mud, sand, or pebbles);

5. amount of aquatic vegetation (visually estimated as none, moderate, or abundant);

6. coverage of the stream by a canopy of trees (visually estimated as none, partial, or nearly full).

\subsection{Analysis of data using the IBI}

Development and modification of the IBI for use in SRS streams is described in detail in Paller et al. (1996). This methodology adjusts for differences in stream size and sample area making it 


\subsection{Analysis of data using the IBI}

Development and modification of the IBI for use in SRS streams is described in detail in Paller et al. (1996). This methodology adjusts for differences in stream size and sample area making it possible to directly compare IBI values from streams and sample areas of different size. The IBI used in this study included species richness, species composition, trophic composition, abundance, indicator species, and fish condition metrics (Table 2), as is typical of most versions of the IBI (Plafkin et al., 1989). IBI values were calculated for each section at each sampling site and then averaged to determine a mean and S.E. for the site.

In addition to the preceding analyses, we compared IBI values from the 13 sites in the streams under study with a data set of 29 IBI values previously calculated for largely undisturbed stream sites on and near the SRS. This data provided an additional measure of the range of variation in IBI values from relatively undisturbed streams. The 29 sites were sampled during 19901995 using methods similar to those used in this study (Paller, 1992). They were located in Meyers branch, Mill creek, Reedy branch, Tinker creek, and undisturbed portions of Hollow creek, Upper Three Runs, Buck creek, Gant's Mill creek, Bodiford Mill creek, Pen branch, and Miller creek. None of the 29 sites suffered from obvious anthropogenic disturbances or point discharges, although some may have been subtly affected by land use practices (i.e. agriculture) in their watersheds.

We employed a nonparametric resampling procedure to determine if the average IBI at any of the sampling sites in our study was significantly different from the average IBI at the 29 undisturbed stream sites. Using Resampling Stats soft-

Table 2

Metrics and scoring criteria used in the $\mathrm{IBI}^{\mathrm{a}}$

Metrics

Scoring criteria

One Three Five

\section{Species richness}

Percentage of expected number of total species

Percentage of expected number of native minnow species

Percentage of expected number of piscivorous species

Percentage of expected number of madtom and darter species

Five

\section{Species composition}

Percent native minnows

Percent sunfish

$\begin{array}{ccc}<70 & 70-90 & >90 \\ <55 & 55-80 & >80 \\ <65 & 65-85 & >85 \\ <55 & 55-80 & >80 \\ & & \\ <20 & 20-35 & >35 \\ <5 \text { and }>45 & 25-45 & 5-24 \\ & & \\ >75 & 50-75 & <50 \\ & & \\ >15 & & <5 \\ & 5-15 & \\ <25 & & \geq 25 \\ <10 & & \geq 10 \\ <5 & & \geq 2 \\ <2 & & \end{array}$

Trophic composition

Percent generalized insectivores

Local indicator species

Percent tolerant fish

Fish abundance (number per $100 \mathrm{~m}^{2}$ )

Stream orders $1-3, \geq 4$ passes $^{b}$

Stream orders $1-3,1$ pass

Stream order $4, \geq 4$ passes

Stream order 4, 1 pass

Fish condition

Percent with disease or anomalies

$>5$

$2-5$

$<2$

\footnotetext{
${ }^{a}$ Individual metrics are assigned scores of one, three, or five.

${ }^{b}$ Passes refer to number of electrofishing passes through the sample reach.
} 


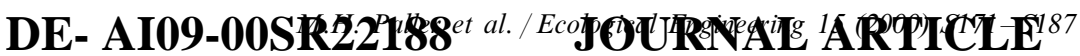

ware (Simon and Bruce, 1991), we randomly drew 10000 samples of four (corresponding to the four sections at most of our sample sites), from the distribution of IBIs from the 29 relatively undisturbed stream sites, calculated a mean for each sample, and plotted the sampling distribution of the means. We considered a mean from one of our 13 sample sites to be significantly lower than the mean for the 29 relatively undisturbed sites if it occurred within the lower $5 \%$ of the sampling distribution of the means for the 29 stream sites $(P \leq 0.05)$. This procedure is a variation of the 'bootstrap' method for computing confidence intervals (Efron, 1982; Noreen, 1989).

\subsection{Analysis of data using multivariate methods}

Multivariate statistical methods compare two or more samples based on the extent to which they share species at similar levels of abundance. Parametric multivariate methods often require that the data meet numerous assumptions and may distort the relationships among samples or generate invalid results if these assumptions are not met. Biological data sets often fail to meet these assumptions because of discontinuous species distributions and the presence of large numbers of zeros. Therefore, we employed two nonparametric methods, nonmetric multidimensional scaling (MDS) and analysis of similarities (ANOSIM) (Clarke and Warwick, 1994), to analyze the fish assemblage data. The former method graphically represents the similarities and differences among communities (with proximity indicative of similarity in assemblage composition), and the latter method statistically tests for the significance of differences between community samples.

Before conducting the MDS, we used the width and length measurements from each section to calculate the surface area of each section. We then converted the catch from each section to areal density (number of fish per $100 \mathrm{~m}^{2}$ ). Earlier research (Paller, 1995) has shown that areal density is more closely related to important fish assemblage metrics, such as species number, than is volumetric density (number of fish per $100 \mathrm{~m}^{3}$ ) in SRS streams. We next $\log _{10}(x+1)$ transformed the data to provide a balanced representation of common and rare species (Clarke and Warwick, 1994). The species by station data matrix used for the MDS consisted of 39 sites (corresponding to the $3930-50 \mathrm{~m}$ sections) and 38 species.

The starting point for the MDS ordination was the Bray-Curtis (Bray and Curtis, 1957) matrix of similarity coefficients based on the $\log _{10}(x+1)$ transformed data. We used 99 iterations to permit the MDS algorithm to develop an ordination with minimal stress (i.e. disagreement between sample similarities indicated by the Bray-Curtis coefficients and sample similarities indicated by distances in the ordination, see Clarke and Warwick, 1994). We constructed both two-dimensional and three-dimensional ordinations but reported only the two-dimensional ordination since it fit the data nearly as well as the three-dimensional one. We calculated spearman rank correlation coefficients between the MDS scores for each site and the densities of individual species at each site to describe the patterns of species composition associated with the MDS scores. We also calculated spearman rank correlation coefficients between the MDS scores and the habitat variables at each site to identify habitat differences associated with spatial patterns of fish assemblage structure. For this analysis, we ranked sediment size on a scale of one to three (one, mud; two, sand; three, pebbles), aquatic vegetation on a scale of one to three (one, none; two, moderate; three, abundant), and canopy cover on a scale of one to three (one, none, or very little; two, partial; and three, full or nearly full).

ANOSIM is a nonparametric permutation procedure that can be used to test for multivariate differences between groups that have been defined a priori. This method utilizes the rank similarities (in this case Bray-Curtis) among samples and determines whether the similarities between samples from different groups are significantly smaller than the similarities among samples from within the groups. We used two groups in our analysis: relatively undisturbed sites (Meyers branch and Upper Three Runs) and recovering sites (Four Mile branch and Pen branch). Total sample size was 39 corresponding to the 39 sections that we sampled. 
In addition to the previously described MDS on 1995 and 1996 data, we conducted an MDS on data from 1995 to 1996 (main channel sites only) and 1990. Methods were comparable to those previously described.

\section{Results}

\subsection{Fish assemblages}

The sample area at Four Mile branch included a single main channel and two side channels (Table 1). The side channels varied in canopy cover from none to partial. The main channel was completely open. The dominant riparian vegetation consisted of grasses and low bushes. We sampled a total stream surface area of $2360 \mathrm{~m}^{2}$ and collected a total of 1950 fish and 32 species. Average fish densities were 275 per 100 and 31 per $100 \mathrm{~m}^{2}$ for the side channels and 38 per $100 \mathrm{~m}^{2}$ for the main channel (Table 3). Considering all Four Mile branch sites together, the dusky shiner and yellowfin shiner were the most abundant species followed by the spotted sunfish, speckled madtom, and redbreast sunfish (Table 4).

The sample area at Meyers branch consisted of only one main channel of fairly uniform width (Table 1). The canopy was largely closed and large trees and grasses were the dominant riparian vegetation. We sampled four sections with a total surface area of $1017 \mathrm{~m}^{2}$ and collected 300 individuals and 19 species. Average fish density was 30 per $100 \mathrm{~m}^{2}$ (Table 3) and the yellowfin shiner was the most abundant species (Table 4). Other relatively abundant species were the American eel, pirate perch and dusky shiner.

Pen branch was divided into several areas that were alternately treated and untreated with herbicide in preparation for replanting in 1995 (Table 1). The treated areas lacked tall trees, and the vegetation was dominated by grasses, briars, bushes and small trees. The untreated area possessed some tall trees but still had a comparatively open or partial canopy. Stream sections B and D were in treated areas and stream section $C$ was in an untreated area. The stream was extremely braided in area $\mathrm{D}$ and progressively less braided as it proceeded upstream to area B. We collected a total of 3251 individuals and 31 species from all Pen branch sites combined. Sample areas ranged from 820 to $1991 \mathrm{~m}^{2}$, and fish densities ranged from 47 to 215 fish per $100 \mathrm{~m}^{2}$. The most numerous species (in all areas combined) was the dusky shiner (Table 4). The yellowfin shiner and spotted sunfish were also abundant.

The sample area at Upper Three Runs included a total of $2198 \mathrm{~m}^{2}$ in one main channel and two braided side channels (Table 1). The canopy cover was dense and provided substantial shading. The location we sampled was in the lower portion of the watershed and subject to frequent flooding by the Savannah river. We collected a total of 515 fish and 26 species. Average densities were 60 and 34 fish per $100 \mathrm{~m}^{2}$ in the side channels and $10 \mathrm{fish}$ per $100 \mathrm{~m}^{2}$ in the main channel (Table 3). The yellowfin shiner, dusky shiner, pirate perch, and tessellated darter were the most numerous species (Table 4).

\subsection{IBI values}

Examination of the individual variables that composed the IBI indicated that most of the sites in the formerly thermal streams (Pen branch and Four Mile) compared favorably with the sites in the relatively undisturbed streams (Meyers branch and Upper Three Runs) (Table 3). An exception was a side channel site in Four Mile branch station 3 which differed from most of the other sites (both formerly thermal and relatively undisturbed) in numerous respects. Other formerly thermal sites exhibited total species numbers, total densities, numbers of cyprinid species, numbers of madtom and darter species, and (in most cases) numbers of piscivorous species equal to or greater than at relatively undisturbed sites. Percent composition variables at the formerly thermal sites were also within the range observed at the relatively undisturbed sites (Table 3). The only IBI variable that generally compared unfavorably at the formerly thermal sites was percentage of tolerant species, which was often higher at the formerly thermal sites because of the abundance of mosquitofish (Table 3). 


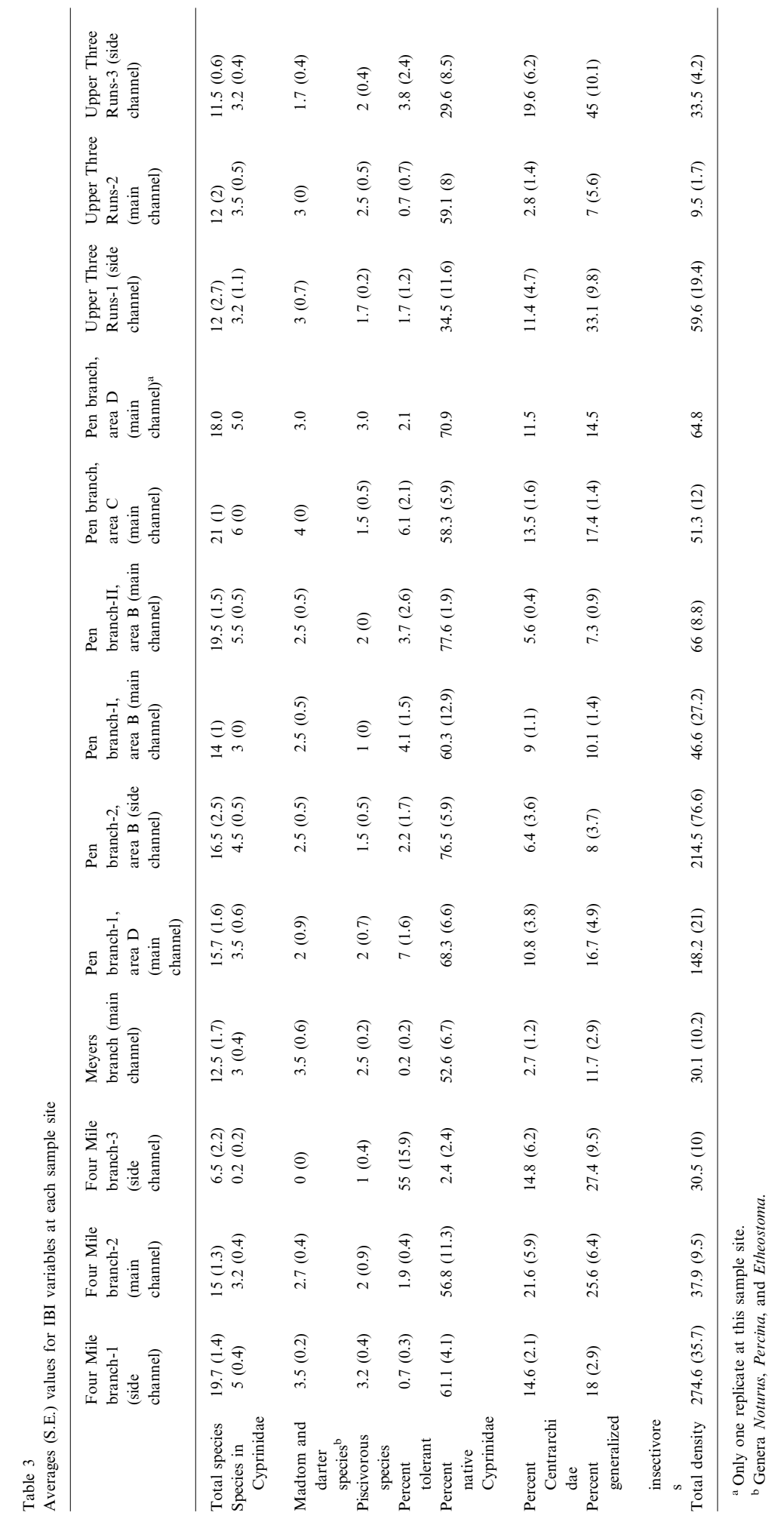




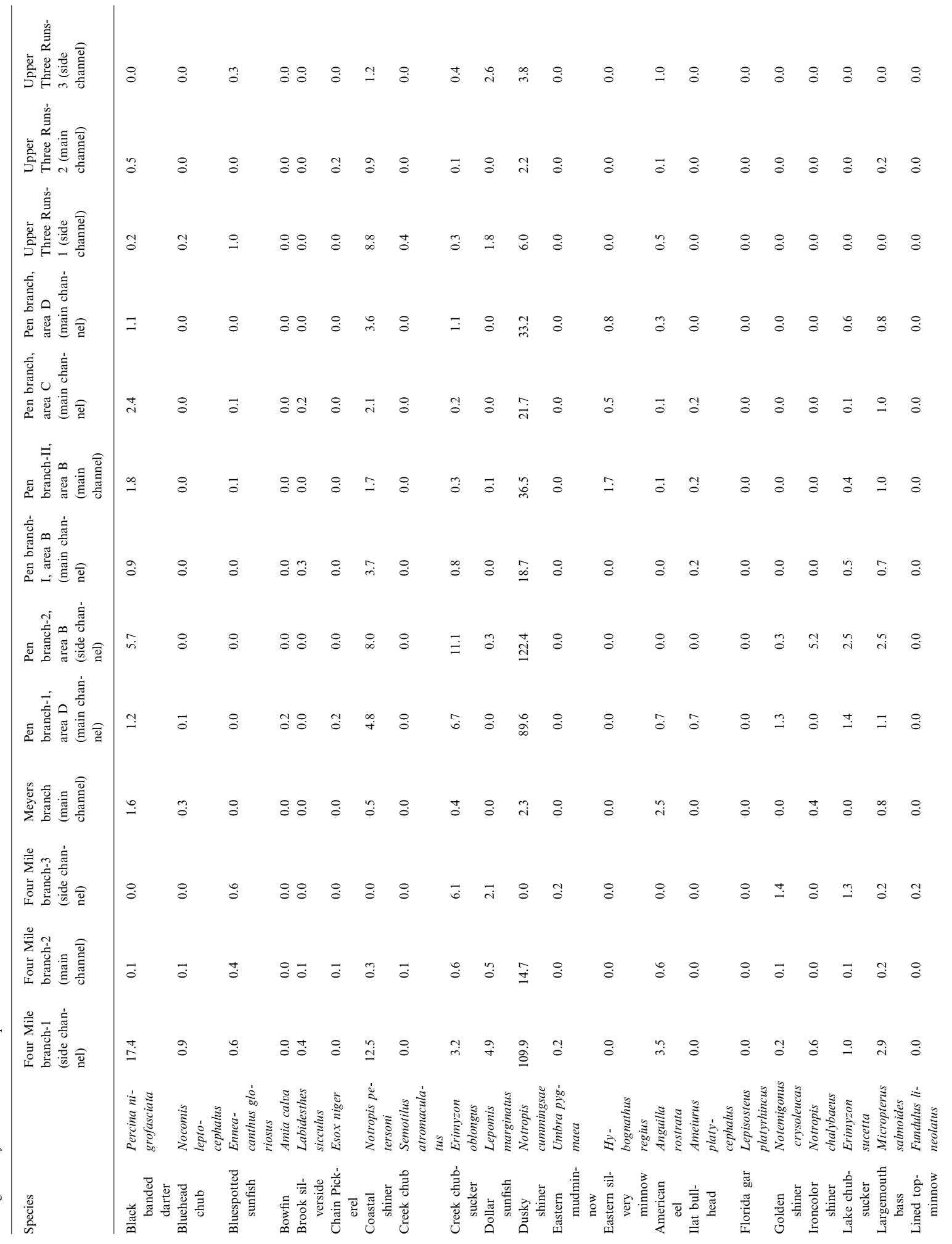




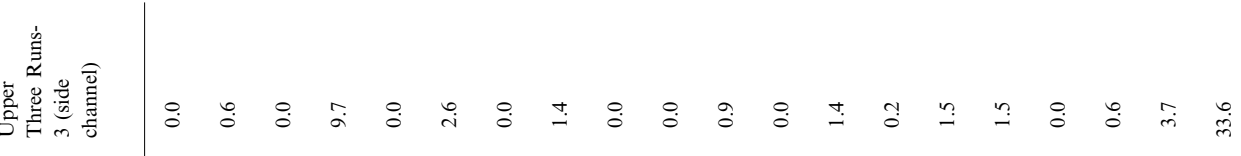

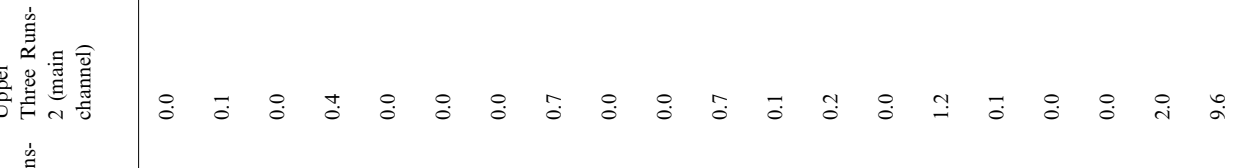

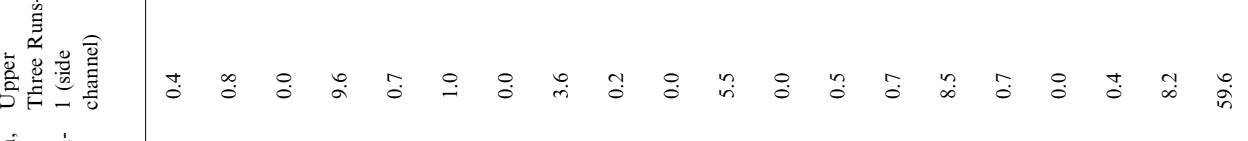

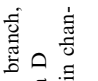

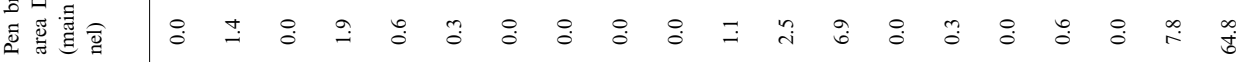

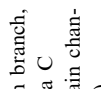

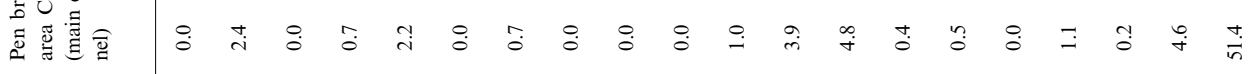

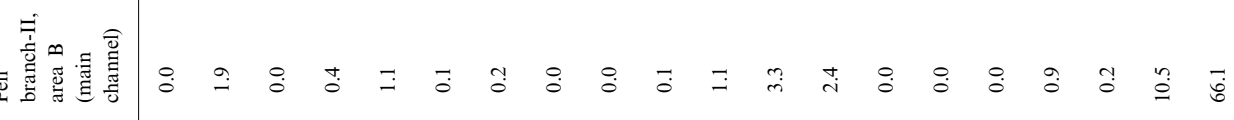

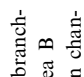

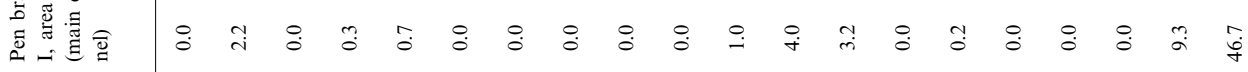

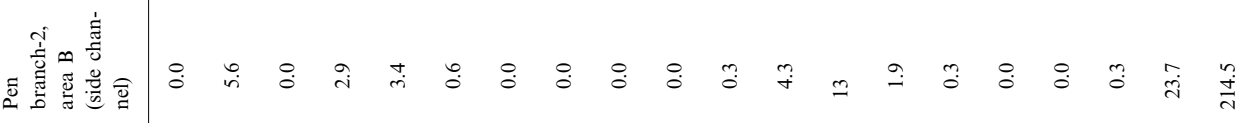

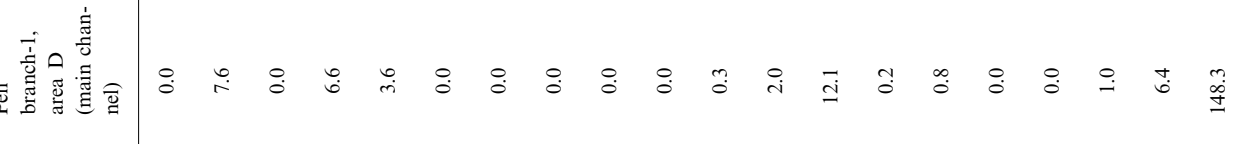

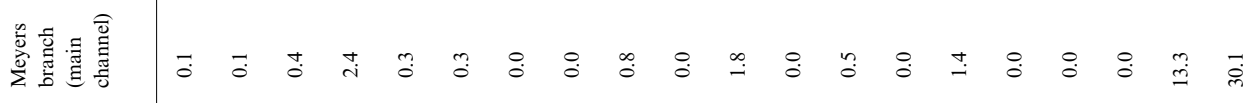

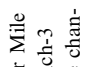

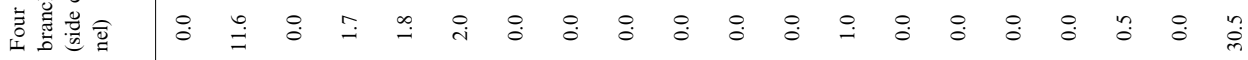

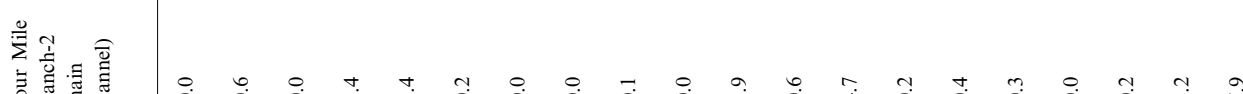

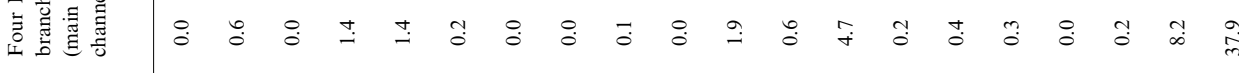
竞实

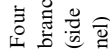

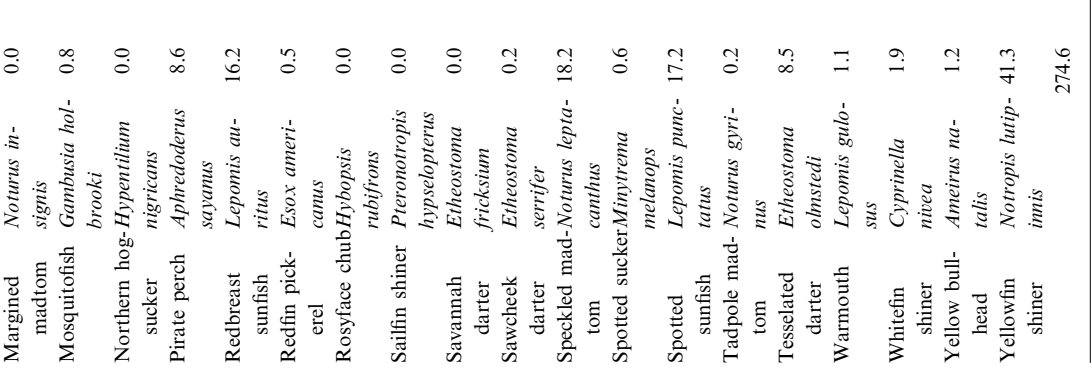




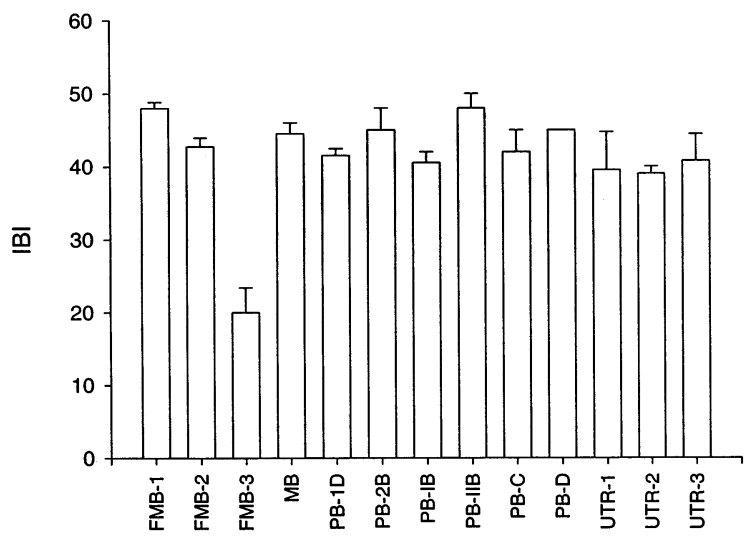

Fig. 1. Comparison of mean (S.E.) IBI values at the 13 sample locations.

IBI values, which were generated by scoring and summing the previously described metrics, were generally comparable between the formerly thermal and relatively undisturbed streams. Excluding Four Mile branch station 3, average IBI values at all sites ranged from approximately 40 to 48 (Fig. 1). The average IBI at Four Mile creek station 3 was only 20 (Fig. 1).

The results of the resampling procedure indicated that the average mean $(n=4)$ for the 29 relatively undisturbed sites sampled during 1990-

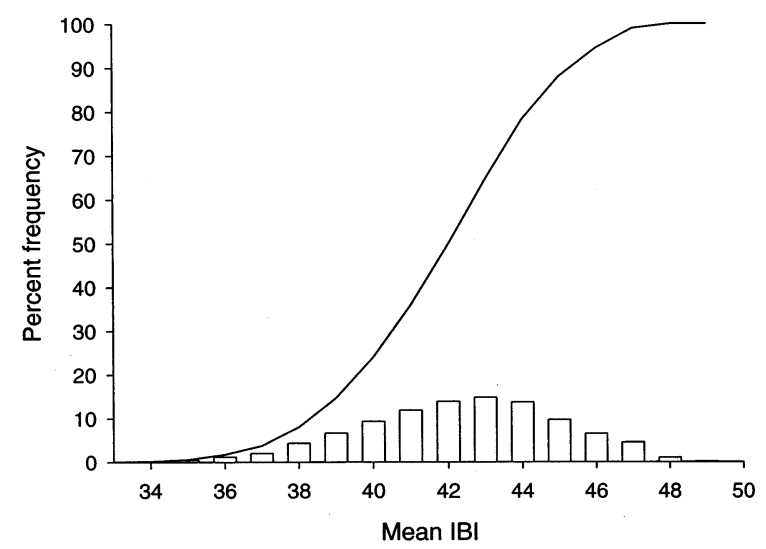

Fig. 2. Distribution of IBI values at 29 relatively undisturbed stream sites. The vertical bars represent the frequency distribution of 10000 means $(n=4)$ randomly drawn from the 29 relatively undisturbed sites (data obtained from Paller, 1992) using a resampling procedure. The line represents the cumulative frequency of means.
1995 was approximately 42 and that $95 \%$ of the means from the relatively undisturbed sites were greater than or equal to approximately 38 (Fig. 2 ). The lowest mean at any of our sites (with the exception of Four Mile station 3) was 39.5. Thus, nearly all of our sites fell within the range expected for relatively undisturbed streams based on the 1990-1995 data. Note that if the randomization procedure was conducted with a sample size of two (the sample size at five of our 13 sites), the sampling distribution of the means would be even wider resulting in an even lower 95\% limit (i.e. less powerful test) and no change in the final results.

\subsection{Multivariate analysis}

MDS scores along axis one (Fig. 3) indicated that the taxonomic composition of the fish assemblages in the side channels (aggregation A in Fig. 3) was often different from that in the main channels (aggregations B and C), regardless of whether the area was disturbed or relatively undisturbed. Spearman rank correlations between MDS scores on axis 1 and the habitat variables indicated that side channels were often relatively shallow, narrow, slow flowing, and characterized by finer sediments (primarily mud). They tended to support redfin pickerel and pirate perch and fewer blackbanded darter and yellowfin shiner. The relative shallowness of many of the side channels also resulted in a scarcity of larger species (e.g. spotted sucker and largemouth bass) compared with the main channels (Fig. 3, Table 4).

The MDS scores along axis two indicated that taxonomic composition often differed between the formerly thermal and relatively undisturbed sites, particularly when this comparison was largely restricted to main channel sites (aggregations B and $\mathrm{C}$ in Fig. 3). Spearman rank correlations between MDS axis two and species densities indicated that the formerly thermal sites were often characterized by higher densities of fish, especially of dusky shiner, redbreast sunfish, spotted sunfish, lake chubsucker, and creek chubsucker (Fig. 3, Table 4). The Four Mile branch main channel sites (which had a slightly longer recovery period) and 

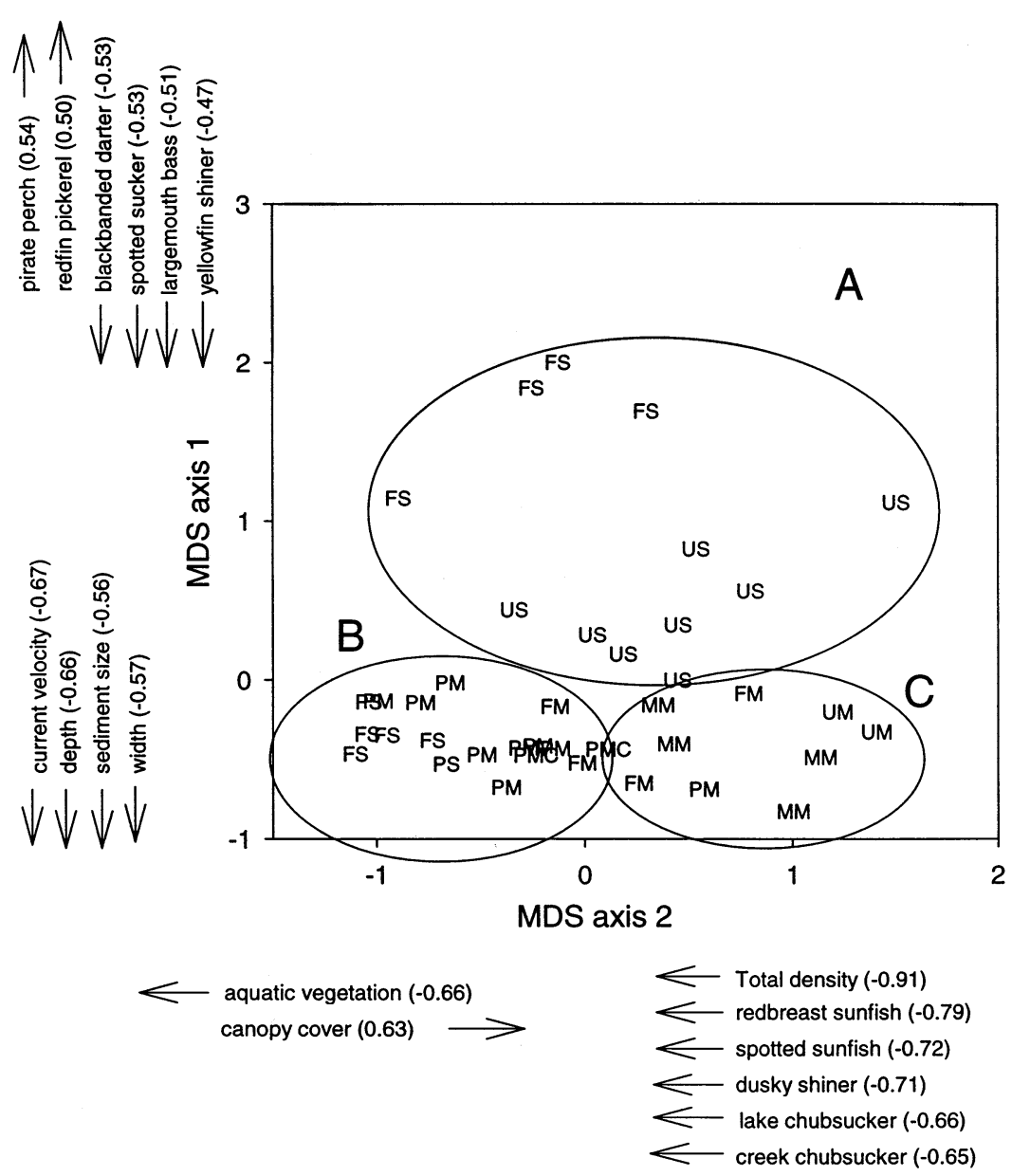

Fig. 3. Nonmetric MDS of fish densities in Four Mile creek (F), Pen branch (P), Meyers branch (M), and Upper Three Runs (U). Second letter indicates side channel (S) or main channel (M) sites. PMC indicates Pen branch main channel sites that were not treated (see text). All other Pen branch sites were in treated areas. A, B, and C designate aggregations of sites discussed in the text. Species densities and habitat factors correlated with the MDS axes (and their spearman rank correlation with the MDS axes) are also shown. Arrows indicate directions of increasing abundance or magnitude.

the untreated Pen branch sites (which had not been disturbed by the herbicide treatment) clustered somewhat closer to the relatively undisturbed main channel sites than did the main channel treatment sites in Pen branch. However, differences between the treated and untreated Pen branch sites were comparatively slight, probably because of the small size of the treated sites and the ability of fish to easily move between treated and untreated areas. Spearman rank correlations between the MDS scores on axis two and the habitat variables indicated that canopy coverage was relatively low and aquatic vegetation coverage relatively high at the disturbed sites.

There were differences between streams within the formerly thermal and relatively undisturbed categories, although these were generally less conspicuous than the differences between categories (Fig. 3, Table 4). Meyers branch and Upper Three Runs, both relatively undisturbed streams, exhibited large differences in yellowfin shiner and pirate perch densities (Table 4). Four Mile branch and Pen branch, both disturbed streams, exhibited large differences in dusky shiner, coastal shiner, and mosquitofish densities. 
The differences in fish assemblage structure between the formerly thermal and relatively undisturbed sites indicated by the MDS were verified by ANOSIM. The results of the ANOSIM (in which all sites were a priori separated into disturbed or relatively undisturbed groups) were significant at $P \leq 0.05$. This analysis indicated that differences in fish assemblage structure among sites within the disturbed and relatively undisturbed categories were not great enough to obscure the differences in assemblage structure that existed between these two categories.

We created an additional MDS plot that included the data collected from the main channel sites in 1995/1996 and the two main channel sites in Pen branch sampled during 1990, when this stream was in an earlier stage of succession (Fig. 4). The relatively large separation on MDS axis one between the 1990 samples from Pen branch and the 1995/1996 samples from all streams (both relatively undisturbed and formerly thermal) presumably reflected changes in fish community structure associated with recovery of the Pen branch ecosystem. Spearman rank correlations between MDS axis two and species densities indicated that these changes consisted largely of decreases in large species including black crappie, suckers, and gars and increases in smaller species including shiners and pirate perch.

\section{Discussion}

Our earlier experiences substantiated the responsiveness of the IBI to environmental conditions characteristic of streams in early stages of
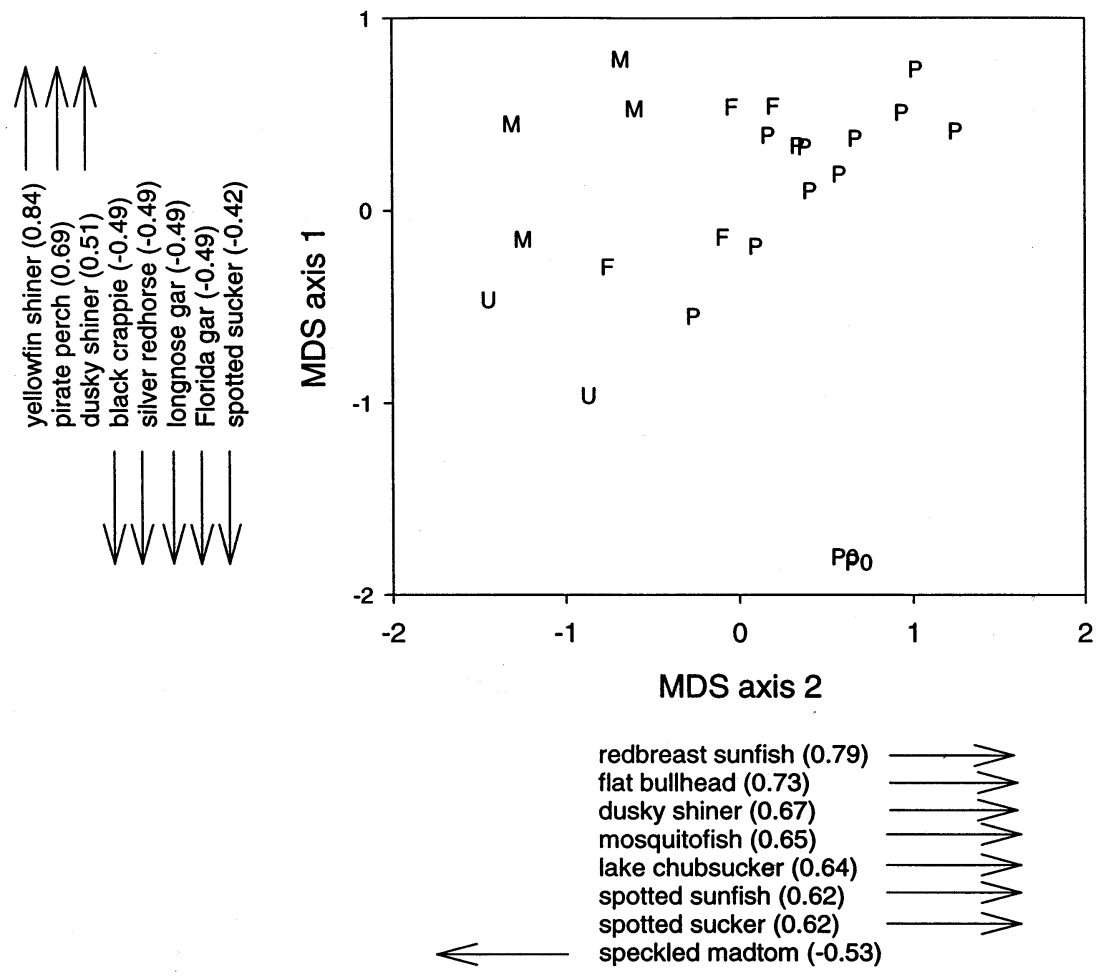

Fig. 4. Nonmetric multidimensional scaling (MDS) of electrofishing samples collected in 1995/1996 from main channel sites in Upper Three Runs (U, undisturbed,), Meyers branch (M, undisturbed), Four Mile branch (F, approximately 10 years since disturbance), and Pen branch (P, approximately 7 years since disturbance). Also shown are electrofishing samples collected from Pen branch in 1990 (PO, approximately 2 years since disturbance). Species densities correlated with the MDS axes (and their Spearman rank correlation with the MDS axes) are shown. Arrows indicate directions of increasing abundance. 
recovery from thermal degradation (Paller et al., 1996). The fish assemblages at that time exhibited typical characteristics of stress such as reductions in number of species and density. However, by $1995 / 1996$ assemblages in the formerly thermal streams exhibited species richness, density, and trophic group composition comparable to or greater than in the relatively undisturbed streams. This is not surprising because species richness, abundance, and diversity during intermediate successional stages are often greater than in mature communities (Odum, 1971). Because differences between the relatively undisturbed and formerly thermal streams in 1995/1996 often involved increases in the abundance of species (e.g. dusky shiner, spotted sunfish) common in undisturbed streams, the IBI did not effectively discriminate between the two types of streams.

IBI development is flexible and, by altering species composition metrics to reflect specific differences between formerly thermal and relatively undisturbed communities, it would be possible to design an IBI that would be more sensitive to succession related changes in SRS streams. We believe that this would be inappropriate since the IBI is intended to be a general measure of biotic integrity, which could be comparatively high, in at least some respects, in a stream undergoing secondary succession. However, the habitat differences between intermediate stages of succession and relatively undisturbed communities result in clear differences in fish assemblage structure. Using methods other than the IBI, these differences can serve to measure the progress of restoration even when intermediate and, perhaps, later stages of succession are attained.

Multivariate statistical analyses clearly summarized the differences in species composition and abundance that existed between fish assemblages in the streams undergoing succession and the relatively undisturbed streams. The particular multivariate techniques that we employed had the advantage of being nonparametric and, therefore relatively robust and assumption free. Theoretically, such methods can accurately measure fish assemblage differences resulting from the habitat changes associated with the entire gradient of recovery. A simple method of accomplishing this is to develop a data matrix consisting of species composition at several relatively undisturbed sites (which would serve as reference points for the range of variation associated with undisturbed communities) and species composition at the sites undergoing restoration. Proximity of the resulting clusters of points in 'ordination space' would serve as a measure of the extent to which the restoration sites resembled the climax sites.

An example of this was the MDS plot that included the 1995 and 1996 data and the 1990 data (Fig. 4). The distance between the 1990 samples from Pen branch and the relatively undisturbed samples in the MDS plot was greater than the distance between the 1995/1996 samples from Pen branch and the relatively undisturbed samples, reflecting the progressive change in fish community structure associated with recovery of the Pen branch ecosystem. The actual positions of the samples in the ordination plot would change if additional time periods were added to the matrix. However, the relative proximities of samples from different recovery periods should still reflect the degree of taxonomic similarity between recovering and relatively undisturbed sites. If desired, a test for statistical significance (such as ANOSIM) could be employed to determine whether differences between different sets of recovery samples and relatively undisturbed samples were statistically significant.

In summary, fish community structure is strongly determined by instream habitat, which is strongly influenced by the surrounding riparian zone and watershed, which, in turn, is strongly influenced by secondary succession during reforestation (Burns, 1972; Keppeler and Ziemer, 1990; Napolitano, 1998). As a result, measuring fish community structure is a reasonable method of assessing restoration success in terms of its effects on stream environments in the South Carolina upper coastal plain. The IBI is sensitive to conditions characteristic of early stages of recovery because fish communities associated with early stages of recovery exhibit clear characteristics of degradation (e.g. low species richness) compared with undisturbed communities. However, the IBI is not the best tool for measuring restoration progress when intermediate states of recovery are 
reached and recovery sites are characterized by elevated abundances of species characteristic of undisturbed conditions. In contrast, multivariate ordination techniques, such as MDS, are potentially sensitive to community changes that occur along the entire recovery gradient and offer a simple visual method of estimating restoration success. Their disadvantage is that they only 'map' differences in species composition and do not provide an ecological interpretation of the basis or biological significance of differences among communities.

A useful approach may be to integrate the two methods with the IBI being used to indicate when recovery has reached the point that many ecologically important aspects of fish assemblage structure have reached levels comparable to relatively undisturbed streams. In addition, many of the metrics included in the IBI, such as density, disease prevalence, and numbers of sensitive species reflect aesthetic and recreational values that may be meaningful in communicating restoration progress to nonspecialists. Multivariate methods, on the other hand, can be used to measure progress towards recovery along the entire recovery gradient because they reflect differences in fish species composition between undisturbed and recovering streams that are likely to persist as long as the habitat differs between these two types of streams.

\section{Acknowledgements}

We acknowledge the valuable assistance of the following people in conducting the sampling, Michael Cameron, Jason Hoyt, Jason Flake, Cindy Metty, Elizabeth Vincent, Jennifer Weitzman, Barbara Bach, Michelle Cunningham, Gina Perez, Stephen Roberts, Paul Truesdale, Sue Klosterhause, Mary Richards, Kim Tugend, Brice Gill, William Driggers, Andrew Bauman. Mary Richards and Loretta Lynch-Reichert are gratefully recognized for their laboratory assistance, data entering and data proofing. Much appreciated assistance in species identification was provided by Dean Fletcher of the Savannah
River Ecology Laboratory and by Ron Ahle of the South Carolina DNR. We thank D.E. Fletcher, F.D. Martin, and L.D. Wike for suggestions that improved this manuscript. This paper is contribution 1190 of the W. Belle Baruck Institute for marine Biology and Coastal Research at the University of South Carolina. This paper was prepared in connection with work under the Department of Energy (Contract DEAC09-89SR 18035).

\section{References}

Angermeier, P.L., Karr, J.R., 1994. Biological integrity versus biological diversity as policy directives. Bioscience 44, 690697.

Bray, J.R., Curtis, J.T., 1957. An ordination of the upland forest communities of southern Wisconsin. Ecol. Monogr. 27, 325-349.

Burns, J.W., 1972. Some effects of logging and associated road construction on northern California streams. Trans. Am. Fish. Soc. 101, 1-17.

Clarke, K.R., Warwick, R.M., 1994. Change in marine communities: an approach to statistical analysis and interpretation. Natural Environment Research Council, UK, p. 144.

Efron, B., 1982. The Jacknife, the Bootstrap, and Other Resampling Plans. SIAM, New York.

Fletcher, D.E., Wilkins, S.D., McArthur, J.V., 2000. Spatial and temporal variation of canopy and macrophyte coverage in response to past thermal disturbance and recent canopy alteration. Ecol. Eng.

Karr, J.R., Dudley, D.R., 1981. Ecological perspective on water quality goals. Environ. Manage. 5, 55-68.

Karr, J.R., Fausch, K.D., Angermeier, P.L., Yant, P.R., Schlosser, I.J., 1986. Assessing biological integrity in running waters: a method and its rationale. Special Publication 5 of the Illinois Natural History Survey.

Keppeler, E.T., Ziemer, R.R., 1990. Logging effects on streamflow: water yields and summer low flows at Caspar creek in northwestern California. Water Resour. Res. 26 (7), 1669-1679.

Napolitano, M., 1998. Persistence of historical logging impacts on channel form in mainstem North Fork Caspar creek. In: Ziemer, R.R. (Ed.), Proceedings of the Conference on Coastal Watersheds: The Caspar Creek Story, 1998 May 6, Ukiah, CA. General Tech. Rep. PSW GTR-168. Albany, CA, Pacific Southwest Research Station, Forest Service, US Department of Agriculture, pp. 97-101.

Noreen, E., 1989. Computer-Intensive Methods for Testing Hypotheses. Wiley, New York.

Odum, E.P., 1971. Fundamentals of Ecology. Saunders, Philadelphia. 


\section{DE- AI09-00SR22188 JOURNAL ARTICLE}

Paller, M.H., 1992. Stream fisheries characterization study. Westinghouse Savannah River Company, Savannah River Laboratory, Aiken, SC, WSRC-RP-92-1034.

Paller, M.H., 1995. Relationships among number of fish species sampled, reach length surveyed, and sampling effort in South Carolina coastal plain streams. N. Am. J. Fish. Manage. 15, 110-120.

Paller, M.H., Reichert, M.J.M., Dean, J.M., 1996. Use of fish communities to assess environmental impacts in South
Carolina coastal plain streams. Trans. Am. Fish. Soc. 125, 633-644.

Plafkin, J.L., Barbour, M.T., Porter, K.D., Gross, S.K., Hughes, R.M., 1989. Rapid bioassessment protocols for use in streams and rivers: benthic macroinvertebrates and fish. EPA/444/4-89-001. US Environmental Protection Agency, Washington, DC.

Simon, J.L., Bruce, P.C., 1991. Resampling Stats. Resampling Stats, Arlington, VA. 